\title{
Cave features, seasonality and subterranean distribution of non-obligate cave dwellers
}

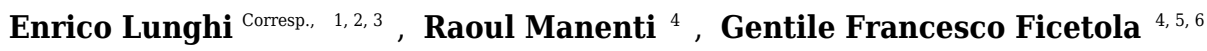 \\ 1 Fachbereich VI Raum-und Umweltwissenschaften Biogeographie, Universität Trier, Trier, Germany \\ 2 Zoology "La Specola", Natural History Museum of University of Florence, Firenze, Firenze, Italia \\ 3 Natural Oasis, Prato, Prato, Italia \\ 4 Department of Bioscience, Università degli Studi di Milano, Milano, Italy \\ 5 Laboratoire d'Ecologie Alpine (LECA), Université Grenoble-Alpes, Grenoble, France \\ 6 LECA, Centre National de la Recherche Scientifique (CNRS), Grenoble, France \\ Corresponding Author: Enrico Lunghi \\ Email address: enrico.arti@gmail.com
}

Seasonality impacts species distributions through changes of the environmental conditions that affect the presence of individuals at a given place. Although the dynamics of cave microclimates is well known, only a few studies have evaluated the effects of such dynamics on non-strictly cave species. Here we assessed if species exploiting subterranean environments show changes in habitat occupation related to seasonal variation of cave microclimates. We surveyed 16 caves in central Italy every month for one year. Caves were subdivided into longitudinal sectors of three meters. In each sector we measured cave morphology and microclimatic features, assessed the occurrence of eight non-troglobitic taxa (orthopterans, spiders, gastropods and amphibians), and related species distribution to environmental features and sampling periods. The occurrence of most species was related to both cave morphology and microclimatic features. The survey month was the major factor determining the presence of species in cave sectors, indicating that cave-dwelling taxa show strong seasonality in activity and distribution. For multiple species, we detected interactions between sampling period and microclimatic features, suggesting that species may associate with different microhabitats throughout the year. The richest communities were found in sites with specific microclimates (i.e. high humidity, warm temperature and low light) but seasonality for species richness was strong as well, stressing the complexity of interactions between outdoor and subterranean environments. 
1 Cave features, seasonality and subterranean distribution of non-obligate cave dwellers

2 Enrico Lunghi ${ }^{1,2,3, *}$, Raoul Manenti ${ }^{4}$, Gentile Francesco Ficetola ${ }^{4,5,6}$

$3 \quad{ }^{1}$ Universität Trier Fachbereich VI Raum-und Umweltwissenschaften Biogeographie, Trier, 4 Germany

$5 \quad 2$ Natural Oasis, Prato, Italy

$6{ }^{3}$ Natural History Museum of University of Florence, Section Zoology "La Specola”, Firenze, 7 Italy

$8{ }^{4}$ Department of Bioscience, Università degli Studi di Milano, Milano, Italy

$9{ }^{5}$ Laboratoire d'Ecologie Alpine (LECA), Université Grenoble-Alpes, Grenoble, France

${ }^{6}$ Centre National de la Recherche Scientifique (CNRS), LECA, Grenoble, France

11

12

*Corresponding author. Tel.:+39 3391604627

13

E-mail addresses: enrico.arti@gmail.com 


\section{Abstract}

16 Seasonality impacts species distributions through changes of the environmental conditions that 17 affect the presence of individuals at a given place. Although the dynamics of cave microclimates 18 are well known, only a few studies have evaluated the effects of such dynamics on non-strictly 19 cave species. Here we assessed if species exploiting subterranean environments show changes in habitat occupation related to seasonal variation of cave microclimates. We surveyed 16 caves in

21 central Italy every month for one year. Caves were subdivided into longitudinal sectors of three 22 meters. In each sector we measured cave morphology and microclimatic features, assessed the 23 occurrence of eight non-troglobitic taxa (orthopterans, spiders, gastropods and amphibians), and 24 related species distribution to environmental features and sampling periods. The occurrence of 25 most species was related to both cave morphology and microclimatic features. The survey month 26 was the major factor determining the presence of species in cave sectors, indicating that cave27 dwelling taxa show strong seasonality in activity and distribution. For multiple species, we 28 detected interactions between sampling period and microclimatic features, suggesting that 29 species may associate with different microhabitats throughout the year. The richest communities 30 were found in sites with specific microclimates (i.e. high humidity, warm temperature and low

31 light) but seasonality for species richness was strong as well, stressing the complexity of 32 interactions between outdoor and subterranean environments. 


\section{Introduction}

Seasonality plays a major role in species distributions by altering the presence of individuals in a given place at a stated time (Murray, Webster \& Bump, 2013). Seasonality may also impact other biological functions of individuals, such as growth, feeding, and reproduction (Araújo et al., 2010; Hjernquist et al., 2012). Among climatic features, air temperature and water availability have a particularly strong impact on species phenology (Kearney et al., 2013), principally on ectotherms (Amarasekare \& Coutinho, 2014; Sheldon \& Tewksbury, 2014), and variation in these features often force animals to search for environments with the most suitable conditions (Papaioannou et al., 2015; Seebacher \& Alford, 2002).

Subterranean environments, from small crevices to deeper holes and caves, are sometimes used as shelters to avoid unfavorable outdoor conditions (Biswas, 2014; Lunghi, Manenti \& Ficetola, 2014; Manenti, 2014), as these environments possess specific microclimatic features which differ from those of surface habitats (Romero, 2009). However, even in such environments the microclimate may not be stable, and fluctuations of primary microclimatic features (temperature, humidity, illuminance) contribute to creating areas characterized by heterogeneous conditions, especially in zones not far from the surface (Campbell Grant, Lowe \& Fagan, 2007; Culver \& White, 2005; Romero, 2012). Species inhabiting such zones are mainly ascribed to troglophiles and trogloxenes, two categories of non-strictly cave species that are able to leave subterranean environments (Sket, 2008). Nevertheless, such species do not occur by chance in subterranean environments, as they need specific combination of environmental features. Consequently, these species tend to occupy zones in which preferred microclimate conditions are realized (Lunghi, Manenti \& Ficetola, 2014). However, only a few studies have 
57 evaluated the effect of cave microclimatic dynamics on non-strictly cave species (Camp et al.,

58 2014; Lunghi, Manenti \& Ficetola, 2015; Mammola, Piano \& Isaia, 2016), leaving incomplete

59 knowledge about species-habitat associations across seasons.

60 In this study we investigated if a group of non-strictly cave species inhabiting 61 subterranean environments changes its distribution through seasons accordingly to cave

62 microclimatic changes. We focused on non-strictly cave species as such species are often

63 considered to use subterranean environments occasionally, and consequently they are likely

64 linked to the characteristics of both outdoor and subterranean environments. Specifically, we

65 investigated a) the occurrence of individual species and b) if the total richness of taxa in a

66 subterranean phase showed stable habitat associations across the year, identifying general

67 patterns and idiosyncrasies of species responses.

Materials \& Methods

70

Surveys

We surveyed 16 caves in the Northern Tuscan Apennines (Central Italy, between $43^{\circ} 52^{\prime} 29^{\prime \prime} \mathrm{N}, 11^{\circ} 13^{\prime} 04^{\prime \prime} \mathrm{E}$ and $43^{\circ} 59^{\prime} 51^{\prime \prime} \mathrm{N}, 10^{\circ} 13^{\prime} 48^{\prime \prime}$ E) monthly from January to December of 2013. We completely explored 13 sites, while the remaining 3 caves were explored until the

75 point at which speleological equipment was indispensable and exploration became too difficult 76 (minimum explored length $=6 \mathrm{~m}$, maximum $=60 \mathrm{~m}$, average $\pm \mathrm{SE}=23.44 \pm 3.94 \mathrm{~m}$ ). All caves

77 were divided into sectors of $3 \mathrm{~m}$ in length, which resulted in 125 cave sectors, considering all the 
78 caves (Table S1). We decided to divide the inner environment into three meters cave sectors, as

79 this subdivision allows adequate characterization of microclimatic variation within caves

80 (Lunghi, Manenti \& Ficetola, 2015). During each survey, we recorded morphological and

81 environmental features for each sector. On a few occasions, some sectors were not accessible

82 because of temporary inaccessibility (e.g., flooding) and missing data represents $2.7 \%$ of the

83 observations. At the end of each sector, we measured maximum height and width using a metric

84 wheel. Furthermore, we estimated average wall heterogeneity (i.e., richness of clefts; Camp \&

85 Jensen, 2007) by placing a string of $1 \mathrm{~m}$ in the middle of the sector and measuring the distance

86 between the two string extremities using a measuring tape. We performed the measures for both

87 right and left walls and calculated the average (Lunghi, Manenti \& Ficetola, 2014). Air

88 temperature and humidity were recorded using a Lafayette TDP92 thermo-hygrometer (accuracy:

$890.1^{\circ} \mathrm{C}$ and $0.1 \%$ ) adopting precautions to avoid influence on cave microclimate (Lopes Ferreira

90 et al., 2015), while the average incident light of sectors was estimated using a Velleman

91 DVM1300 light meter (minimum recordable light: 0.1 lux).

We performed 12 monthly surveys in each cave and the interval between two consecutive surveys in the same cave varied between 9 and 45 days, to have surveys for every month of the year. All 3 m-sectors were re-sampled by the same person, who dedicated 7.5 minutes to each sector to assess the presence of species using visual encounter surveys (Crump \& Scott, 1994). troglophilic taxa within each cave sector: one orthopteran (Dolichopoda laetitiae), three spiders 
100 (Meta menardi, Metellina merianae, and Tegenaria sp.), two gastropods (Chilostoma planospira 101 and Limax sp.) and two anuran amphibians (Rana italica and Bufo bufo). The species were 102 selected due to their common presence in caves and their easy identification without invasive 103 methods, giving us the opportunity to collect data limiting disturbance and changes in individual 104 behaviour. Furthermore these species show significant variation in life history and ecological 105 traits. The cave cricket Dolichopoda laetitiae is generally abundant in subterranean environments 106 of Central Italy (Allegrucci et al., 2014). These crickets are scavengers of subterranean 107 environments but can also feed outside caves, thus increasing the supply of allochthonous 108 organic matter into the caves (Lavoie, Helf \& Poulson, 2007; Weckerly, 2012). The three arachnid species exploit subterranean environments for a significant part of their lives and are among the major cave predators (Manenti, Lunghi \& Ficetola, 2015; Novak et al., 2010). We 111 grouped all detected individuals as Tegenaria sp. because identifying spiders at the species level 112 in the genus Tegenaria is difficult without using invasive methods (Bolzern, Burckhardt \& 113 Hänggi, 2013). Chilostoma planospira is a snail that feeds on vegetal organic matter and even 114 lichens (Albano et al., 2014; Baur et al., 2007), while the genus Limax contains large slugs 115 (Limax were only identified to genus) that feed on residual organic matter (Horsák, Zelený \& Hájek, 2014). The frog Rana italica and the toad Bufo bufo frequently exploit caves but mostly

117 use these habitats as shelter (Bonini, Razzetti \& Barbieri, 1999; Lunghi, Manenti \& Ficetola, 118 2014). 
122 standard regression analyses (MacKenzie et al., 2006). Approaches have been developed to take

123 this into account in regression models (MacKenzie et al., 2006), but they generally require

124 multiple surveys being performed within periods without changes due to birth, death, and

125 movement of individuals to and from the population (closed populations; MacKenzie et al.,

126 2006). Considering the time interval between most of surveys, the assumption of closed

127 populations was likely not met (MacKenzie et al., 2006), making the application of these

128 methods difficult. We therefore used two complementary approaches to control for the potential

129 effects of imperfect detection. First, caves were surveyed using a standardized study design to

130 limit variation in detection rate among sectors, and we dedicated the same sampling effort to all

131 sectors during all seasons. Under standardized monitoring efforts, analyses taking and not taking

132 into account imperfect detection generally produce consistent results (Banks-Leite et al., 2014).

133 We thus analyzed data with generalized linear mixed models (GLMMs). This approach allows

134 for heterogeneity of species distribution among caves and sectors, even though it does not

135 integrate imperfect detection. Subsequently, we repeated analyses using approaches allowing to

136 integrate imperfect detection, to assess the robustness of GLMMs analyses.

Analysis with mixed models.

We identified the relationship between species and cave features using GLMMs assuming

binomial error. The presence of each species was considered as a dependent variable while cave

141 features (microclimatic and morphological) were considered as independent variables. As each

142 cave was visited 12 times, cave and sector identity were used as random factors, while month of 
143 survey was included as a categorical variable. To test if species tend to frequent different

144 microclimatic zones during a given time, we also considered the interaction between month

145 (sampling period) and microclimatic features as independent variables. All possible

146 combinations of independent variables were built and ranked using the Akaike's Information

147 Criterion corrected for small sample size (AICc) (Fang, 2011). For each species, we first built

148 GLMMs using all possible combinations of independent variables and the model with the lowest

149 AICc values was considered the best AICc model. Complex models showing AICc values

150 greater than simpler, nested models were not considered in the set of candidate models

151 (Richards, Whittingham \& Stephens, 2011). Variables were transformed using logarithms or

152 square root to better fit the normal distribution when necessary. Likelihood ratio tests were used

153 to assess the significance in terms of the best AICc models.

Analyses taking into account imperfect detection.

Species tend to move across sectors during different periods of the year because of the generally assume that multiple surveys are performed during short periods in which occupancy is constant (MacKenzie et al., 2006). We therefore used occupancy modelling to calculate the detection probability for each species, on the basis of pairs of surveys that were performed within 14 days, as these periods may better ensure meeting the assumption of closed populations (MacKenzie et al., 2006). To calculate detection probability of species we used 35 pairs of surveys, performed in all caves and across seasons within an interval which did not exceed 14 
165 data using standard general linear models, while weighing absences on the basis of the detection

166 probability of species (Gómez-Rodríguez et al., 2012). Such an approach allows us to integrate

167 imperfect detection even when only one survey per period is performed (Gómez-Rodríguez et al., 168 2012).

Integrating random factors into this analysis is not possible, thus, cave identity was

171 independent variables, and ranked them following AICc. We tested the significance of variables

172 included in the best-AICc model using a likelihood ratio test (Bolker et al., 2008). error. In addition to the eight focal taxa, we also integrated data on the distribution of two species that were frequently observed in the caves, but were not considered in single-species analyses: the salamander Hydromantes italicus and the spider Amaurobius ferox. The salamander Hydromantes italicus was the focus of a previously published study performed in the same area (Lunghi, Manenti \& Ficetola, 2015) and represents one of the top predators of the studied taxa. calculated for each sector represented the dependent variable, while microclimatic features (temperature, humidity and light) and their relative interaction with the sampling period (month) were the independent variables. The individual caves and their sectors were used as random 186 factors. All statistical analyses were performed with program R using packages lme4, MuMIn, 
187 MASS and unmarked (Bartoń, 2013; Bates et al., 2015; Fiske \& Chandler, 2011; The R 188 Foundation for Statistical Computing, 2016; Venables \& Ripley, 2002).

189

190

191

193

194

195

196

197

198

199

200

201

202

203

204

205

206

207

\section{9}

\section{Results}

A total of 1,918 observations of the eight focal taxa were recorded among the 16 caves (and 125 cave sectors) during the 12-month study. The most frequent species was Metellina merianae, followed by Tegenaria sp., and Meta menardi. Less frequent species were Dolichopoda laetitiae, Chilostoma planospira and Limax sp. The other two species Rana italica and Bufo bufo were less common. Observations of taxa are summarized in Table S2. Per-visit detection probability of species ranged between 0.44 and 0.73 (Table S2). Correlation between microclimatic variables was weak (for all comparisons, $|\mathrm{r}|<0.11$ ), indicating that collinearity is not a problem for our models.

\section{a) Species distribution}

The distribution of species varied among cave sectors over time. For all taxa, we detected significant relationships between occurrences, survey period, and the environmental features recorded (Table 1), but these relationships were highly variable amongst species. For all taxa, results of both mixed models and GLMs considering imperfect detection were generally consistent, although some relationships were detected by just one of these analyses. The occurrence of the cricket $D$. laetitiae was negatively related to sector height and light, and positively related to wall heterogeneity and temperature. The best AICc models also included the 
208 interactions between month and humidity (Table 2a; Table S3a). From winter to early spring this

209 cricket occupied sectors characterized by high humidity, while in late summer and autumn it was

210 associated with less humid sectors (Fig. 1a). Furthermore, the best mixed model also included

211 the interaction between month and light (Table 2a), while the best model considering imperfect

212 detection also included a positive relationship with width of sector and the interaction between

213 month and temperature (Table S3a).

Within the arachnofauna, occurrence of $M$. menardi was positively related with sector

width, and negatively with height and light. Interactions between month and light and between month and temperature were also included in the best AICc model (Table 2b; Table S3b). From late summer to winter this spider occupied sectors with warmer temperatures, while sectors with low light were preferred during the whole year (Fig. 1b and 1c). Furthermore, the best mixed model also included a positive relationship with sector humidity (Table $2 \mathrm{~b}$ ). The frequency of $M$. menardi was higher in autumn. The occurrence of $M$. merianae was positively related with sector temperature; the highest frequencies of the species were detected between spring and autumn

222 (Table 2c; Table S3c). The best mixed model also suggested a negative relationship with sector height and light, and detected an interaction between month and light (Table 2c), while the best model considering imperfect detection also included a negative relationship with humidity (Table S3c). The occurrence of Tegenaria was negatively related to light. Furthermore, there was a significant interaction between month and light (Table 2d; Table S3d), as the relationships

227 between these spiders and low light was particularly evident in winter (Fig. 1d), a period in 228 which the species was particularly frequent in caves. Furthermore, the best mixed model also 229 included a positive relationship with sector temperature and a negative one with width (Table 
230 2d), while the best GLM also included a negative relationship with sector humidity and height,

231 and the interaction between humidity and month (Table S3d).

The interaction between month and microclimatic features was never included in the best-

233

234

235

236

237

238 AICc model of gastropods, while the month of survey was always included (Table 2e-f). The occurrence of $C$. planospira was negatively related with sector height (Table 2e; Table S3e) and occurrences were higher during spring and summer. The best mixed models also included a negative relationship with sector width and light (Table 2e). For Limax slugs we did not detect any relationship with the examined cave features, however, its occurrence was higher during summer and early autumn (Table 2f; Table S3f).

The occurrence of Rana italica was negatively related to light and wall heterogeneity, and positively related to sector width and height (Table $2 \mathrm{~g}$; Table $\mathrm{S} 3 \mathrm{~g}$ ). The best mixed model also included the interaction between month and light (Table $2 \mathrm{~g}$ ), while the best model considering imperfect detection included a negative relationship with sector humidity (Table S3g). Finally, the occurrence of B. bufo was positively related to sector height (Table 2h; Table S3h); the best mixed model included also a negative relationship with temperature (Table $2 \mathrm{~h}$ ).

In this study, we did not include cave depth as an additional variable in models assessing species distribution, because distance from the entrance was strongly related to multiple features of caves, such as light and humidity, and including strongly correlated variables into regression models can bias the regression outcomes (Dormann et al., 2013), making model selection particularly hard (Cade, 2015). For instance, the negative correlation between sector and incident light was very strong $(\mathrm{r}=-0.94)$. However, distance from cave entrance often affects the distribution of non-trogblobitic species (Lavoie, Helf \& Poulson, 2007), thus we repeated 
252 analyses adding distance from the entrance to the best AICc-models. Adding distance reduced

253 the AICc values of the best models of all species except Bufo bufo, and the relationship between

254 depth and species occurrence was negative for most of taxa (Table S5). This suggests that the

255 majority of study taxa are actually found nearby the cave entrance. Nevertheless, adding cave

256 depth to our models did not modify the coefficients of relationships between species and

257 microhabitat features (Table S5), therefore our conclusions are not affected by the decision to not

258 include depth in regression models.

259

260

b) Species richness

261

Species richness was mainly related to microclimatic features (Table S4). The richest

262

communities were positively related to sector humidity $\left(\chi^{2}{ }_{1}=9.7, P=0.002\right)$ and temperature

$\left(\chi^{2}{ }_{1}=98.3, P<0.001\right)$, while negatively related with light $\left(\chi^{2}{ }_{1}=62.8, P<0.001\right)$. These

relationships determined a shift of the sectors with highest richness through the year. During winter, species richness was more evenly distributed among all cave sectors (Fig. 2a), while in spring and summer the highest richness tended to be more concentrated toward the cave entrance

267 (Fig 2b-c).

\section{Discussion}

Species distributions

All the species tend to occupy areas in which their physiological requirements are 
273 conditions (e.g. microclimate) are suitable. Survey month was a major factor determining the

274 presence of species in caves, as it was present in nearly all best models (Tables 2 and S3). This

275 fact underlines the high seasonality of species distributions, even for populations exploiting

276 subterranean habitats. In the extreme case of Limax slugs, month was the only variable included

277 in the best AICc model (Table 2f). These slugs did not show any significant relationship with the

278 considered microhabitat features, but the occurrence of these gastropods was strongly affected by

279 period of the year. For nearly all the species, the highest occurrence was detected during spring

280 and summer months, periods in which ectothermal animals are generally more active, and food

281 availability is high (Bale \& Hayward, 2010).

Physical and morphological cave features (e.g. width, height and wall heterogeneity of

inner environment) were very important, especially for invertebrate predators. Meta menardi showed an association with sectors characterized by a low cave roof. This predator hunts through both active search and sit-and-wait strategies, so constructing its web in sectors where the ceiling is not far from the ground might increase rates of prey capture in webs. However, cave morphology did not only influence predators. Non-predator species could also be influenced by sector structure, such as Dolichopoda laetitiae and Chilostoma planospira. The cricket D. laetitiae was associated with sectors characterized by high irregularity, and many clefts which may have given the opportunity to better avoid predators. Chilostoma planospira was related to sectors in which food availability might be higher, as this species frequented areas characterized by high passage which in turn have more wall surface, as this feature is positively related with 293 the abundance of lichens (Manenti, 2014). 
296 tolerance, thus, the limited microclimatic excursion of cave environments may have a limited

297 effect on the presence of this species. Furthermore, in three studied taxa we detected clear

298 interactions between month and microclimatic features (Table 2, Fig. 1). These interactions may

299 occur for several reasons. In some cases the species may select the same microhabitat across the

300 seasons and mitigate within the caves, selecting areas with suitable microclimate over the year.

301 For instance, a previous study on the same group of caves showed that cave salamanders are

302 consistently associated with sectors having a temperature of $10-15{ }^{\circ} \mathrm{C}$ (Lunghi, Manenti \&

303 Ficetola, 2015); in summer these conditions represent the coolest sector, while in winter these

304 are the conditions of warmest sectors. As a consequence, the relationship between salamander

305 occurrence and temperature is positive during winter and negative during summer (Lunghi,

306 Manenti \& Ficetola, 2015). However, the significant interaction between environmental

307 variables and month suggests taxa were associated with different microhabitats during different

308 periods. Species were associated with the darkest or most humid sectors in winter, while in

309 summer they were found in superficial sectors with more light and less humidity (Fig 1). Warmer

310 sectors were more often inhabited during winter (Fig. 1). For most of the species, activity peaks

311 are reached in summer, when individuals are generally closer to the surface. Conversely, during

312 winter periods, species become less active and tend to occupy deeper sectors of caves, where

313 prolonged suitable conditions may let them reduce costs linked to acclimatization (Angilletta Jr.,

314 Niewiarowski \& Navas, 2002) (Fig. 1).

Our study shows that at least for the populations considered, cave exploitation is not random and occurs during the whole year. Moreover, at least for the relatively superficial cave

317 sectors, the distribution of species is strongly related to the different cave microclimatic features, 318 and to their seasonal variation during the year. Seasonal effects are extremely important, and are 
319 a major driver of species distribution (Sheldon \& Tewksbury, 2014). In caves, the seasonality

320 occurring in shallow sectors is generally higher than in the deepest parts, where temperature

321 shows very limited variation (Ravbar \& Kosutnik, 2014). Nevertheless, even at the cave entrance

322 microclimatic conditions are significantly more stable than in outdoor environments (Ray,

323 Beever \& Rodhouse, 2016).

During the year, the highest species richness was found in sectors with specific microclimatic conditions (i.e., high humidity, warm temperature and low light). These conditions are usually realized in sectors that are not far from the entrance, but are deep enough to prevent excessive light exposure (Culver \& White, 2005). However, the cave area in which such a combination is realized is not static, thus its location is not fixed but changes depending on surface environmental influence. For example, the stronger the external influence, the deeper the suitable area. In such zones, individuals are protected from extreme external thermic fluctuations but, when external condition are suitable, they are able to reach external foraging sites (Fang, 2011). Distance from the entrance is certainly important for the distribution of most of study species (Table S5), but it is strongly related to the microclimatic features, which actually explain most of variation in species distribution (Table S5). Therefore, we did not include distance as predictor in our models, given that focusing on microclimatic features allows to better characterize the most likely determinant of species 
341 might be due to the presence of cryptic access to the main cave environment. In cave studies the

342 main entrances (where humans can get in) are generally considered to be the sole accesses to

343 inner environments. However, even if that is true for humans, small animals can use small

344 fractures and passages to enter cave environments. In fact, in the two longest examined caves,

345 respectively at 48 and $57 \mathrm{~m}$ of depth, the presence of interstitial openings likely permits species

346 to enter and exit from cave environments without passing through the main entrance.

Study limitations

In our study we standardized surveys in order to minimize the impact of variation of applying occupancy modeling to our data can complicate data interpretation. Indeed, in the results it is not easy to distinguish between true variation in occupancy and variation in detection probability.

To confirm the appropriateness of results, we repeated analyses by integrating the detection probability of each species. The outcome confirmed that mixed model were generally robust, as $70 \%$ of relationships detected by mixed models were confirmed by analyses considering imperfect detection. When sites are surveyed only once per period, weighted GLMs can allow us to take into account imperfect detection (Gómez-Rodríguez et al., 2012). However, this approach also has some limitations. Given that standard implementations do not allow including random factors, it hampers our ability to fully consider the effects of spatial heterogeneity, and the potential impacts of cave and sector identity on species distribution. Under these situations, a 
362 comparison between the two approaches can be the best approach to identify the most consistent

363 relationships, thus obtaining more robust results.

364

365 Conclusion

366

Cave communities are often considered to be less affected by seasonality than communities from the surface. The species surveyed in our study belong to two different types of nonstrictly cave dwelling organisms: usually epigean species normally considered to exploit caves during certain part of the year or during part of the day, and species resident close to cave entrances (e.g. Meta and Metellina spiders). Our study also shows that the limited seasonal environment is strong enough to modify the distributions of nonstrictly cave dwelling species. Indeed, cave environments are not simple refuge for these taxa, but they actually are habitats with dynamic features. This stresses the complexity of interactions between outdoor and subterranean environments. As a consequence, studies on the ecology of cave environments should take into account the dynamism of nonstrictly cave-dwelling species as an active seasonal feature. Future studies are needed to understand the spatial extent of such seasonal influences.

\section{Acknowledgements}

We thank P. Blaimont for linguistic revisions, and two reviewers for comments on previous drafts of the manuscript. 


\section{Supplemental Information}

384 Supplementary data associated with this article can be found, in the online version. 


\section{References}

Albano PG, D'occhio P, Strazzari G, Succetti F, and Sabelli B. 2014. Land-mollusc forest communities along an altitudinal transect in northern Italy. Journal of Molluscan Studies 80:55-61. 10.1093/mollus/eyt041

Allegrucci G, Rampini M, Di Russo C, Lana E, Cocchi S, and Sbordoni V. 2014. Phylogeography and systematics of the westernmost Italian Dolichopoda species (Orthoptera, Rhaphidophoridae). ZooKeys 437:1-23. 10.3897/zookeys.437.7917

Amarasekare P, and Coutinho RM. 2014. Effects of temperature on intraspecific competition in ectotherms. The American Naturalist 184:E50-E65. 10.1086/677386

Angilletta Jr. MJ, Niewiarowski PH, and Navas CA. 2002. The evolution of thermal physiology in ectotherms. Journal of Thermal Biology 27:249-268.

Araújo CS, Candido DM, Araújo HFP, Dias SC, and Vasconcellos A. 2010. Seasonal variations in scorpion activities (Arachnida: Scorpiones) in an area of Caatinga vegetation in northeastern Brazil. Zoologia 27:372-376.

Bale JS, and Hayward SAL. 2010. Insect overwintering in a changing climate. The Journal of Experimental Biology 213:980-994. 10.1242/jeb.037911

Banks-Leite C, Pardini R, Boscolo D, Righetto Cassano C, Püttker T, Santos Barros C, and Barlow J. 2014. Assessing the utility of statistical adjustments for imperfect detection in tropical conservation science. Journal of Applied Ecology 51:849-859. 10.1111/1365-2664.12272

Bartoń K. 2013. MuMIn: multi-model inference. $R$ package.

Bates D, Maechler M, Bolker B, and Walker S. 2015. Fitting Linear Mixed-Effects Models Using Ime4. Journal of Statistical Software 67:1-48. 10.18637/jss.v067.i01

Baur B, Cremene C, Groza G, Schileyko AA, Baur A, and Erhardt A. 2007. Intensified grazing affects endemic plant and gastropod diversity in alpine grasslands of the Southern Carpathian mountains (Romania). Biologia 62:438-445. 10.2478/s11756-007-0086-4

Biswas J. 2014. Occurrence and distribution of cave dwelling frogs of peninsular India. Ambient Science 1:17-25.

Bolker BM, Brooks ME, Clark CJ, Geange SW, Poulsen JR, Stevens MHH, and White J-SS. 2008. Generalized linear mixed models: a practical guide for ecology and evolution. Trends in Ecology and Evolution 24:127-135. 10.1016/j.tree.2008.10.008

Bolzern A, Burckhardt D, and Hänggi A. 2013. Phylogeny and taxonomy of European funnel-web spiders of the Tegenaria-Malthonica complex (Araneae: Agelenidae) based upon morphological and molecular data. Zoological Journal of the Linnean Society of London 168:723-848. 10.1111/zoj.12040

Bonini L, Razzetti E, and Barbieri F. 1999. Cave breeding of Bufo bufo (Linnaeus, 1758) in Liguria (North west Italy). In: Miaud C, and Guyétant R, eds. Current studies in herpetology. Le Bourget du Lac: SEH, 59-61.

Cade BS. 2015. Model averaging and muddled multimodel inferences. Ecology 96:2370-2382. 10.1890/14-1639.1

Camp CD, and Jensen JB. 2007. Use of twilight zones of caves by plethodontid salamanders. Copeia:594604.

Camp CD, Wooten JA, Jensen JB, and Bartek DF. 2014. Role of temperature in determining relative abundance in cave twilight zones by two species of lungless salamander (family Plethodontidae). Canadian Journal of Zoology 92:119-127. 
430

431

432

433

434

435

436

437

438

439

440

441

442

443

444

445

446

447

448

449

450

451

452

453

454

455

456

457

458

459

460

461

462

463

464

465

466

467

468

469

470

471

472

473

474

475

476

Campbell Grant EH, Lowe WH, and Fagan WF. 2007. Living in the branches: population dynamics and ecological processes in dendritic networks. Ecology Letters 10:165-175. 10.1111/j.14610248.2006.01007.x

Crump ML, and Scott NJ. 1994. Visual Encounter Surveys. In: Heyer WR, Donnelly MA, McDiarmid RW, Hayek LC, and Foster MS, eds. Measuring and monitoring biological diversity: standard methods for Amphibians. Washington: Smithsonian Institution Press, 84-92.

Culver DC, and White WB. 2005. Encyclopedia of caves: Elsevier Academic Press.

Dormann CF, Elith J, Bacher S, Buchmann C, Carl G, Carré G, García Marquéz GR, Gruber B, Lafourcade B, Leitão PJ, Münkemüller T, McClean C, Osborne PE, Reineking B, Schröder B, Skidmore AK, Zurell D, and Lautenbach S. 2013. Collinearity: a review of methods to deal with it and a simulation study evaluating their performance. Ecography 36:27-46. 10.1111/j.1600-0587.2012.07348.x

Fang Y. 2011. Asymptotic equivalence between cross-validations and Akaike Information Criteria in Mixed-Effects Models. Journal of Data Science 9:15-21.

Fiske I, and Chandler R. 2011. unmarked: an R package for fitting hierarchical models of wildlife occurrence and abundance. Journal of Statistical Software 43:1-23. http://www.jstatsoft.org/v43/i10/

Gómez-Rodríguez C, Bustamante J, Díaz-Paniagua C, and Guisan A. 2012. Integrating detection probabilities in species distribution models of amphibians breeding in Mediterranean temporary ponds. Diversity and Distributions 18:260-272. 10.1111/j.1472-4642.2011.00837.x

Hjernquist MB, Söderman F, Jönsson KI, Herczeg G, Laurila A, and Merilä J. 2012. Seasonality determines patterns of growth and age structure over a geographic gradient in an ectothermic vertebrate. Oecologia 170:641-649. 10.1007/s00442-012-2338-4

Horsák M, Zelený D, and Hájek M. 2014. Land snail richness and abundance along a sharp ecological gradient at two sampling scales: disentangling relationships. Journal of Molluscan Studies 80:256-264. 10.1093/mollus/eyu027

Kearney M, and Porter W. 2009. Mechanistic niche modelling: combining physiological and spatial data to predict species ranges. Ecology Letters 12:334-350. 10.1111/j.1461-0248.2008.01277.x

Kearney MR, Simpson SJ, Raubenheimer D, and Kooijman SALM. 2013. Balancing heat, water and nutrients under environmental change: a thermodynamic niche framework. Functional Ecology 27:950-965. 10.1111/1365-2435.12020

Lavoie KH, Helf KL, and Poulson TL. 2007. The biology and ecology of North American cave crickets. Journal of Cave and Karst Studies 69:114-134.

Lopes Ferreira R, Mendes Martins V, Arantes Paixão E, and Souza Silva M. 2015. Spatial and temporal fluctuations of the abundance of Neotropical cave-dwelling moth Hypena sp. (Noctuidae, Lepidoptera) influenced by temperature and humidity. Subterranean Biology 16:47-60. 10.3897/subtbiol.16.5137

Lunghi E, Manenti R, and Ficetola GF. 2014. Do cave features affect underground habitat exploitation by non-troglobite Species? Acta Oecologica 55:29-35. http://dx.doi.org/10.1016/j.actao.2013.11.003

Lunghi E, Manenti R, and Ficetola GF. 2015. Seasonal variation in microhabitat of salamanders: environmental variation or shift of habitat selection? PeerJ 3:e1122. 10.7717/peerj.1122

MacKenzie DI, Nichols JD, Royle JA, Pollock KH, Bailey LL, and Hines JE. 2006. Occupancy estimation and modeling. Inferring patterns and dynamics of species occurrence: Academic Press.

Mammola S, Piano E, and Isaia M. 2016. Step back! Niche dynamics in cave-dwelling predators. Acta Oecologica 75:35-42. http://dx.doi.org/10.1016/j.actao.2016.06.011

Manenti R. 2014. Dry stone walls favour biodiversity: a case-study from the Appennines. Biodiversity and Conservation 23. 10.1007/s10531-014-0691-9 
477

478

479

480

481

482

483

484

485

486

487

488

489

490

491

492

493

494

495

496

497

498

499

500

501

502

503

504

505

506

507

508

509

510

511
Manenti R, Lunghi E, and Ficetola GF. 2015. Distribution of spiders in cave twilight zone depends on microclimatic features and trophic supply. Invertebrate Biology 134:242-251. 10.1111/ivb.12092

Murray BD, Webster CR, and Bump JK. 2013. Broadening the ecological context of ungulate-ecosystem interactions: the importance of space, seasonality, and nitrogen. Ecology 94:1317-1326.

Novak T, Tkavc T, Kuntner M, Arnett AE, Lipovšek Delakorda S, Perc M, and Janžekovič F. 2010. Niche partitioning in orbweaving spiders Meta menardi and Metellina merianae (Tetragnathidae). Acta Oecologica 36:522-529. 10.1016/j.actao.2010.07.005

Papaioannou H, Sgardelis S, Chondropoulos B, Vassilakis D, Kati V, and Dimopoulos P. 2015. Demographic characteristics, seasonal range and habitat topography of Balkan chamois population in its southernmost limit of its distribution (Giona mountain, Greece). Journal of Natural History 48:327-345. 10.1080/00222933.2013.869365

Ravbar N, and Kosutnik J. 2014. Variations of karst underground air temperature induced by various factors (Cave of Županova jama, Central Slovenia). Theoretical and Applied Climatology 116:327341. 10.1007/s00704-013-0955-4

Ray C, Beever EA, and Rodhouse TJ. 2016. Distribution of a climate-sensitive species at an interior range margin. Ecosphere 7:e01379. 10.1002/ecs2.1379

Richards SA, Whittingham MJ, and Stephens PA. 2011. Model selection and model averaging in behavioural ecology: the utility of the IT-AIC framework. Behavioral Ecology and Sociobiology 65:77-89. 10.1007/s00265-010-1035-8

Romero A. 2009. Cave Biology. Cambridge, UK: Cambridge University Press.

Romero A. 2012. Caves as biological space. Polymath: An Interdisciplinary Arts and Sciences Journal 2:115.

Seebacher F, and Alford RA. 2002. Shelter microhabitats determine body temperature and dehydration rates of a terrestrial amphibian (Bufo marinus). Journal of Herpetology 36:69-75.

Sheldon KS, and Tewksbury JJ. 2014. The impact of seasonality in temperature on thermal tolerance and elevational range size. Ecology 95:2134-2143.

Sket B. 2008. Can we agree on an ecological classification of subterranean animals? Journal of Natural History 42:1549-1563. 10.1080/00222930801995762

The R Foundation for Statistical Computing. 2016. R version 3.3.1

Venables WN, and Ripley BD. 2002. Modern Applied Statistics with S. Fourth Edition. New Yourk: Springer.

Weckerly FW. 2012. Cave cricket exit counts: environmental influences and duration of surveys. Journal of Cave and Karst Studies 74:1-6. 10.4311/2011LSC0223 


\section{Figure 1 (on next page)}

Figure 1. Variation of relationship between the presence of species and microclimatic features.

For each microclimatic feature (illuminance, temperature and humidity) we show the coefficients of regression models analyzing the different months separately. Positive values indicate that in a given month the species is positively associated with the variable, and so on. Analyses are limited to species by variable combinations for which a significant interaction between month and the variable is included in both GLMMs and GLM best AICC model (see Tab.1). Missing values correspond to months in which the models showed convergence issues, due to the limited sample size; error bars are two standard errors. 
a)

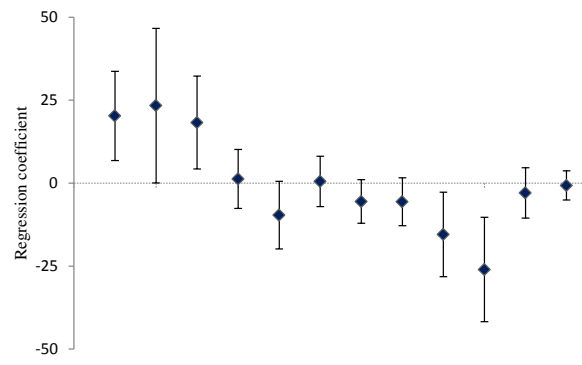

c)

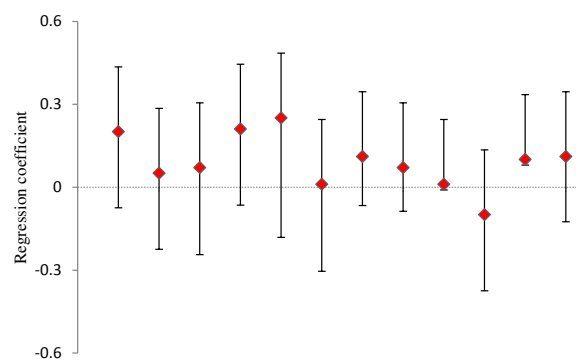

b)

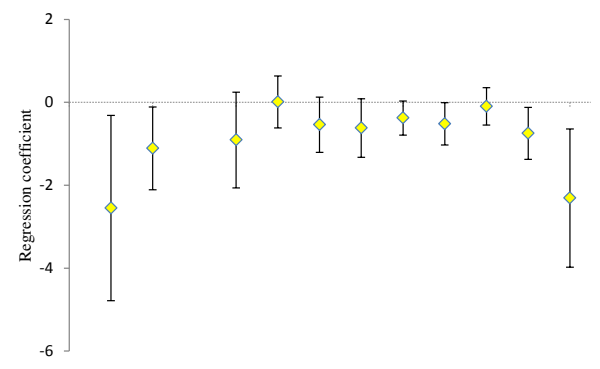

d)

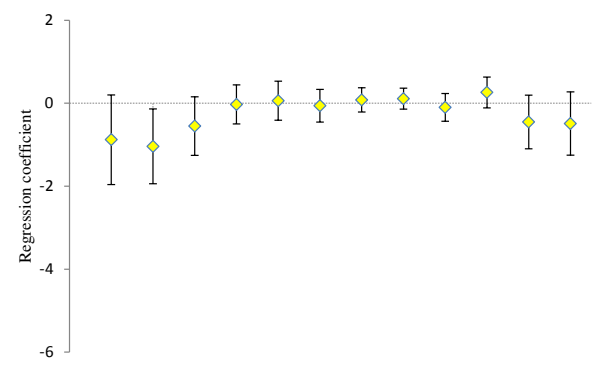

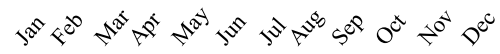

$$
\begin{aligned}
& \text { Illuminance } \\
& \text { Temperature } \\
& \text { Humidity }
\end{aligned}
$$




\section{Figure 2 (on next page)}

Figure 2. Seasonal variation of species richness.

Average species richness estimated for each sector during the whole year 2013. Winter:

January - March; Spring: April - June; Summer: July - September; Autumn: October December. Error bars represent standard errors. 

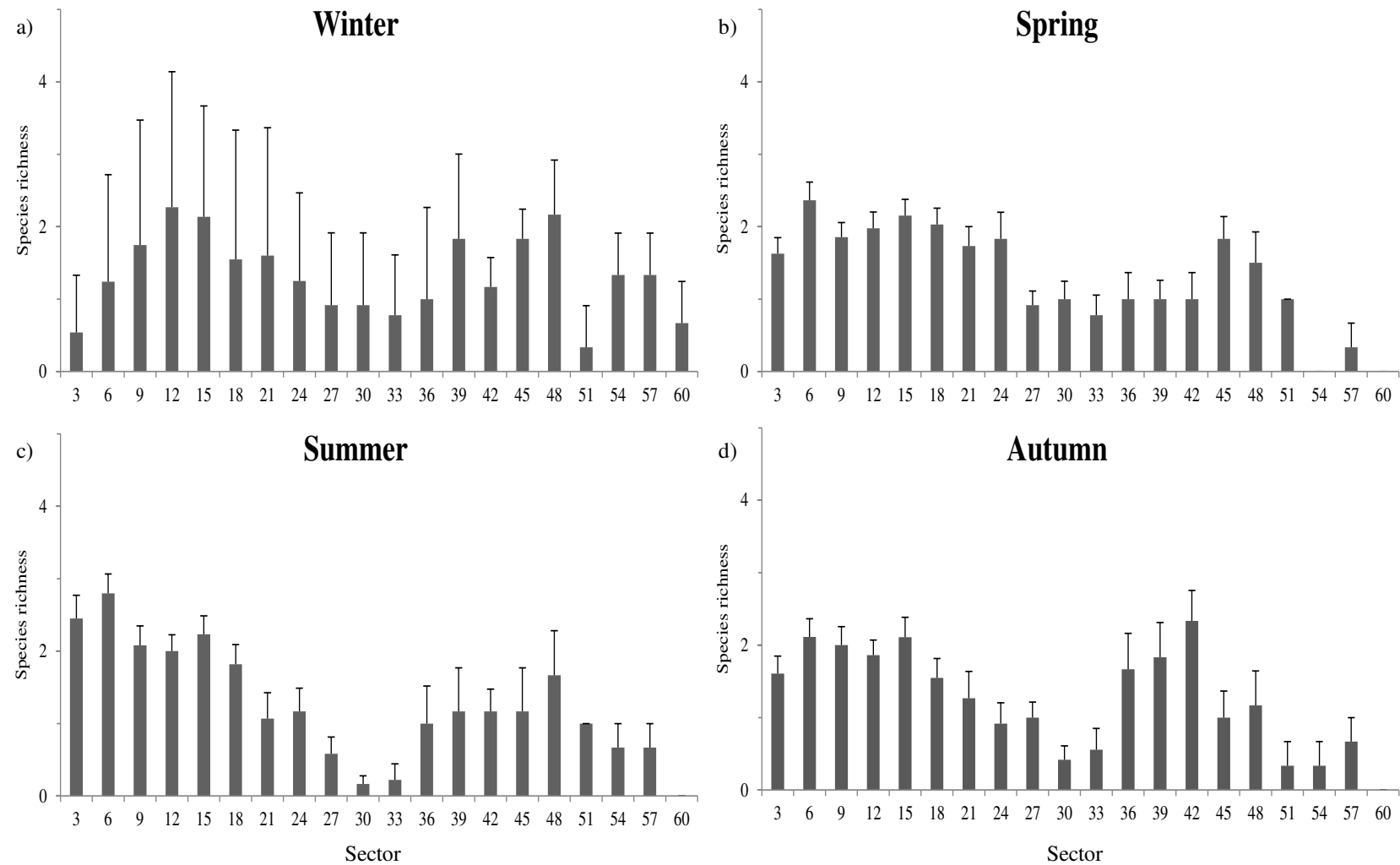


\section{Table $\mathbf{1}$ (on next page)}

Table 1. The best five models based on AICc relating the presence of each taxon.

Presence of species a-h) were considered as dependent variables. Independent variables are:

wall heterogeneity (Het), humidity (Humid), month of survey, minimum illuminance (Lux), temperature (Temp), height and width of sectors. Interaction $\left(^{\mathrm{x}}\right.$ ) between month (M) and microclimatic features were considered as further independent variables. The symbol $X$ indicates the presence of variables in models. 
1 Table 1 The best five models based on AICc relating the presence of each taxon. Presence of

2 species a-h) were considered as dependent variables. Independent variables are: wall

3 heterogeneity (Het), humidity (Humid), Month of survey, minimum illuminance (Lux),

4 temperature (Temp), Height and Width of sectors. Interaction ( $\left.{ }^{*}\right)$ between Month (M) and

5 microclimatic features were considered as further independent variables. The symbol X indicates

6 the presence of variables into models.

\begin{tabular}{|c|c|c|c|c|c|c|c|c|c|c|c|c|c|}
\hline \multicolumn{10}{|c|}{ Independent variables included into the model } & \multirow[t]{2}{*}{ df } & \multirow[t]{2}{*}{ AICc } & \multirow[t]{2}{*}{$\Delta$-AICc } & \multirow[t]{2}{*}{ weight } \\
\hline Het & Humid & Month & Height & Width & Lux & $\begin{array}{c}\text { Tem } \\
\text { p }\end{array}$ & $\begin{array}{l}\text { Hum } \\
{ }^{\times} \mathbf{M}\end{array}$ & $\begin{array}{l}\mathbf{L u x} \\
{ }^{\times} \mathbf{M}\end{array}$ & $\begin{array}{c}\text { Tem } \\
\mathbf{p}^{\times} \\
\mathbf{M}\end{array}$ & & & & \\
\hline & \multicolumn{13}{|c|}{ a) Dolichopoda laetitiae } \\
\hline $\mathbf{X}$ & $\mathbf{X}$ & $\mathbf{X}$ & $\mathbf{X}$ & & $\mathbf{X}$ & $\mathbf{X}$ & $\mathbf{X}$ & $\mathbf{X}$ & & 41 & 889 & $\mathbf{0}$ & 0.628 \\
\hline $\mathrm{X}$ & $\mathrm{X}$ & $\mathrm{X}$ & $\mathrm{X}$ & $\mathrm{X}$ & $\mathrm{X}$ & $\mathrm{X}$ & $\mathrm{X}$ & $\mathrm{X}$ & & 42 & 890.5 & 1.5 & 0.297 \\
\hline $\mathrm{X}$ & $\mathrm{X}$ & $\mathrm{X}$ & $\mathrm{X}$ & & $\mathrm{X}$ & $\mathrm{X}$ & $\mathrm{X}$ & $\mathrm{X}$ & $\mathrm{X}$ & 52 & 895.2 & 6.20 & 0.028 \\
\hline $\mathrm{X}$ & $\mathrm{X}$ & $\mathrm{X}$ & $\mathrm{X}$ & $\mathrm{X}$ & $\mathrm{X}$ & $\mathrm{X}$ & $\mathrm{X}$ & $\mathrm{X}$ & $\mathrm{X}$ & 53 & 896.4 & 7.43 & 0.015 \\
\hline \multirow[t]{3}{*}{$\mathrm{X}$} & & $\mathrm{X}$ & $\mathrm{X}$ & & $\mathrm{X}$ & $\mathrm{X}$ & & & $\mathrm{X}$ & 29 & 898.3 & 9.45 & 0.006 \\
\hline & \multicolumn{13}{|c|}{ b) Meta menardi } \\
\hline & $\mathbf{X}$ & $\mathbf{X}$ & $\mathbf{X}$ & $\mathbf{X}$ & $\mathbf{X}$ & $\mathbf{X}$ & & $\mathbf{X}$ & $\mathbf{X}$ & 41 & 1224.1 & $\mathbf{0}$ & 0.344 \\
\hline \multirow[t]{2}{*}{$X$} & $\mathrm{X}$ & $\mathrm{X}$ & $\mathrm{X}$ & $\mathrm{X}$ & $\mathrm{X}$ & $\mathrm{X}$ & & $\mathrm{X}$ & $\mathrm{X}$ & 42 & 1226.1 & 2.03 & 0.125 \\
\hline & $\mathrm{X}$ & $\mathrm{X}$ & $\mathrm{X}$ & & $\mathrm{X}$ & $\mathrm{X}$ & & $\mathrm{X}$ & $\mathrm{X}$ & 40 & 1226.5 & 2.41 & 0.103 \\
\hline \multirow[t]{3}{*}{$X$} & $\mathrm{X}$ & $\mathrm{X}$ & & & $\mathrm{X}$ & $\mathrm{X}$ & & $\mathrm{X}$ & $\mathrm{X}$ & 40 & 1227.4 & 3.33 & 0.065 \\
\hline & & $\mathrm{X}$ & $\mathrm{X}$ & $\mathrm{X}$ & $\mathrm{X}$ & $\mathrm{X}$ & & $\mathrm{X}$ & $\mathrm{X}$ & 40 & 1227.5 & 3.43 & 0.062 \\
\hline & \multicolumn{13}{|c|}{ c) Metellina merianae } \\
\hline \multirow{10}{*}{$\mathrm{X}$} & & $\mathbf{X}$ & $\mathbf{X}$ & & $\mathbf{X}$ & $\mathbf{X}$ & & $\mathbf{X}$ & & 28 & 1424.7 & $\mathbf{0}$ & 0.174 \\
\hline & & $\mathrm{X}$ & & & $\mathrm{X}$ & $\mathrm{X}$ & & $\mathrm{X}$ & & 28 & 1425.2 & 0.55 & 0.133 \\
\hline & & $\mathrm{X}$ & & $\mathrm{X}$ & $\mathrm{X}$ & $\mathrm{X}$ & & $\mathrm{X}$ & & 28 & 1425.6 & 0.88 & 0.112 \\
\hline & $\mathrm{X}$ & $\mathrm{X}$ & $\mathrm{X}$ & & $\mathrm{X}$ & $\mathrm{X}$ & & $\mathrm{X}$ & & 29 & 1426.4 & 1.72 & 0.074 \\
\hline & & $\mathrm{X}$ & $\mathrm{X}$ & $\mathrm{X}$ & $\mathrm{X}$ & $\mathrm{X}$ & & $\mathrm{X}$ & & 29 & 1426.7 & 2.04 & 0.063 \\
\hline & \multicolumn{13}{|c|}{ d) Tegenaria sp. } \\
\hline & & $\mathbf{X}$ & & $\mathbf{X}$ & $\mathbf{X}$ & $\mathbf{X}$ & & $\mathbf{X}$ & & 28 & 1256.1 & $\mathbf{0}$ & 0.107 \\
\hline & & & & $\mathrm{X}$ & $\mathrm{X}$ & $\mathrm{X}$ & & & & 6 & 1256.8 & 0.69 & 0.076 \\
\hline & $\mathrm{X}$ & $\mathrm{X}$ & & $\mathrm{X}$ & $X$ & $\mathrm{X}$ & & $\mathrm{X}$ & & 29 & 1257 & 0.91 & 0.068 \\
\hline & & $\mathrm{X}$ & $\mathrm{X}$ & & $X$ & $X$ & & $\mathrm{X}$ & & 28 & 1257.1 & 1.01 & 0.065 \\
\hline \multirow[t]{5}{*}{$X$} & & $\mathrm{X}$ & & & $\mathrm{X}$ & $\mathrm{X}$ & & $\mathrm{X}$ & & 28 & 1257.5 & 1.35 & 0.055 \\
\hline & e) Chilo & ma plan & pira & & & & & & & & & & \\
\hline & & $X$ & $\mathbf{X}$ & $\mathbf{X}$ & $\mathbf{X}$ & & & & & 17 & 868.3 & 0 & 0.072 \\
\hline & & $\mathrm{X}$ & $\mathrm{X}$ & $\mathrm{X}$ & $\mathrm{X}$ & $\mathrm{X}$ & & & & 18 & 868.9 & 0.61 & 0.053 \\
\hline & & $\mathrm{X}$ & $\mathrm{X}$ & $\mathrm{X}$ & $\mathrm{X}$ & & & $\mathrm{X}$ & & 28 & 869 & 0.78 & 0.049 \\
\hline \multirow[t]{3}{*}{$\mathrm{X}$} & & $\mathrm{X}$ & $\mathrm{X}$ & & X & & & & & 17 & 869.2 & 0.96 & 0.045 \\
\hline & & & $\mathrm{X}$ & $\mathrm{X}$ & $\mathrm{X}$ & & & & & 7 & 869.4 & 1.16 & 0.040 \\
\hline & \multicolumn{13}{|c|}{ f) Limax sp. } \\
\hline $\mathbf{X}$ & & $\mathbf{X}$ & & $\mathbf{X}$ & & & & & & 16 & 703 & 0 & 0.061 \\
\hline \multirow[t]{5}{*}{$X$} & & $\mathrm{X}$ & & & & & & & & 15 & 703.1 & 0.06 & 0.059 \\
\hline & & $\mathrm{X}$ & $\mathrm{X}$ & & & & & & & 15 & 703.1 & 0.07 & 0.059 \\
\hline & & $\mathrm{X}$ & & $\mathrm{X}$ & & & & & & 15 & 703.6 & 0.63 & 0.045 \\
\hline & & $\mathrm{X}$ & & & & & & & & 14 & 703.7 & 0.65 & 0.044 \\
\hline & g) Rana & lica & & & & & & & & & & & \\
\hline $\mathbf{X}$ & & $\mathbf{X}$ & $\mathbf{X}$ & $\mathbf{X}$ & $\mathbf{X}$ & & & $\mathbf{X}$ & & 29 & 526.4 & 0 & 0.244 \\
\hline $\mathrm{X}$ & & $\mathrm{X}$ & $\mathrm{X}$ & X & $X$ & & & & & 18 & 526.7 & 0.35 & 0.205 \\
\hline $\mathrm{X}$ & & $\mathrm{X}$ & $\mathrm{X}$ & $\mathrm{X}$ & $\mathrm{X}$ & $\mathrm{X}$ & & & & 19 & 527.7 & 1.29 & 0.128 \\
\hline X & & $\mathrm{X}$ & $\mathrm{X}$ & X & $X$ & $\mathrm{X}$ & & $\mathrm{X}$ & & 30 & 528.1 & 1.73 & 0.103 \\
\hline $\mathrm{X}$ & $\mathrm{X}$ & $\mathrm{X}$ & $X$ & $\mathrm{X}$ & $\mathrm{X}$ & & & $\mathrm{X}$ & & 30 & 528.4 & 2.08 & 0.086 \\
\hline & h) $B u f o$ & & & & & & & & & & & & \\
\hline $\mathbf{X}$ & & & $\mathbf{X}$ & & & $\mathbf{X}$ & & & & 6 & 200.3 & $\mathbf{0}$ & 0.109 \\
\hline & & & $\mathrm{X}$ & & & $X$ & & & & 5 & 200.4 & 0.08 & 0.105 \\
\hline $\mathrm{X}$ & & & $\mathrm{X}$ & & $\mathrm{X}$ & $\mathrm{X}$ & & & & 7 & 200.5 & 0.17 & 0.1 \\
\hline & & & $\mathrm{X}$ & $\mathrm{X}$ & & $\mathrm{X}$ & & & & 6 & 201.1 & 0.79 & 0.073 \\
\hline & & & $\mathrm{X}$ & & $\mathrm{X}$ & $\mathrm{X}$ & & & & 6 & 201.4 & 1.06 & 0.064 \\
\hline
\end{tabular}




\section{Table 2 (on next page)}

Parameters related to the presence of species. For each species we show significance of variables included in the relative best AICC model.

The first eight species (a-h) are those included in this study, while data for the last species (Hydromantes italicus) are taken from another study performed in the same area (Lunghi et al., 2015). Shaded variables are those included in the best model of the same species identified by GLM (only for species studied in this work). 
1 Table 2: Parameters related to the presence of species. For each species are shown significance

2 of variables included in the relative best AICc model. First eight species (a-h) are the species

3 included in this study, while data for the last species (Hydromantes italicus) are taken from

4 another study performed in the same area (Lunghi et al., 2015). Shaded variables are those

5

\begin{tabular}{rlrrr}
\cline { 2 - 5 } 6 & \multicolumn{1}{c}{ Factor } & \multicolumn{1}{c}{$\chi^{2}$} & $\chi^{2}{ }_{1}$ & $P$ \\
\cline { 2 - 5 } 7 & a) D. laetitiae & & & \\
& & & & \\
8 & Month & & 99.91 & $<\mathbf{0 . 0 0 1}$ \\
& Heterogeneity & 0.40 & 13.25 & $<\mathbf{0 . 0 0 1}$ \\
& Height & -0.42 & 14.68 & $<\mathbf{0 . 0 0 1}$ \\
& Humidity & 7.79 & 0.01 & 0.919 \\
& Lux & -25.13 & 24.68 & $<\mathbf{0 . 0 0 1}$ \\
10 & Temperature & 0.56 & 35.07 & $<\mathbf{0 . 0 0 1}$ \\
& Hum $\times$ Month & & 40.26 & $<\mathbf{0 . 0 0 1}$ \\
11 & Lux $\times$ Month & & 40.49 & $<\mathbf{0 . 0 0 1}$ \\
& & &
\end{tabular}

12

b) M. menardi

13

$\begin{array}{lrrr}\text { Month } & & 65.36 & <\mathbf{0 . 0 0 1} \\ \text { Width } & 0.13 & 4.52 & \mathbf{0 . 0 3 3} \\ \text { Height } & -0.18 & 6.29 & \mathbf{0 . 0 1 2} \\ \text { Humidity } & 3.71 & 5.55 & \mathbf{0 . 0 1 8} \\ \text { Lux } & -2.3 & 31.42 & <\mathbf{0 . 0 0 1} \\ \text { Temperature } & -0.07 & 0.93 & 0.334 \\ \text { Tem } \times \text { Month } & & 33.72 & <\mathbf{0 . 0 0 1} \\ \text { Lux } \times \text { Month } & & 34.89 & <\mathbf{0 . 0 0 1}\end{array}$

c) M. merianae

\begin{tabular}{|c|c|c|c|}
\hline Month & & 19.23 & 0.057 \\
\hline Height & -0.03 & 10.79 & 0.001 \\
\hline Lux & -3.14 & 226.73 & $<0.001$ \\
\hline Temperature & 0.13 & 14.57 & $<0.001$ \\
\hline Lux $\times$ Month & & 33.72 & $<0.001$ \\
\hline
\end{tabular}

d) Tegenaria $s p$.

\begin{tabular}{|lrrr|}
\hline Month & & 15.17 & 0.175 \\
\hline Width & -0.1 & 17.64 & $<\mathbf{0 . 0 0 1}$ \\
\hline Lux & -1.17 & 28.62 & $<\mathbf{0 . 0 0 1}$ \\
\hline Temperature & 0.11 & 7.44 & $\mathbf{0 . 0 0 6}$ \\
\hline Lux $\times$ Month & & 30.59 & $\mathbf{0 . 0 0 1}$ \\
\hline
\end{tabular}

included in the best model of the same

e) C. planospira

$\begin{array}{lrl}\text { Month } & 62.69<\mathbf{0 . 0 0 1}\end{array}$

$\begin{array}{llll}\text { Height } & 0.11 & 5.45 & \mathbf{0 . 0 1 9}\end{array}$

$\begin{array}{llll}\text { Width } & -0.13 & 6.36 & \mathbf{0 . 0 1 2}\end{array}$

$\begin{array}{llll}\text { Lux } & -0.27 & 6.06 & \mathbf{0 . 0 1 4}\end{array}$

f) Limax sp.

$\begin{array}{lrrr}\text { Month } & & 91.78 & <\mathbf{0 . 0 0 1} \\ \text { Heterogeneity } & 0.15 & 2.67 & 0.102\end{array}$

$\begin{array}{llll}\text { Width } & -0.12 & 2.11 & 0.147\end{array}$

g) R. italica

Month $\quad 33.96<\mathbf{0 . 0 0 1}$

Heterogeneity $\quad-4.62 \quad 17.73<\mathbf{0 . 0 0 1}$

$\begin{array}{llll}\text { Width } & 0.34 & 7.34 & \mathbf{0 . 0 0 7}\end{array}$

Height $\quad 0.28 \quad 12.90<\mathbf{0 . 0 0 1}$

Lux $\quad-27.5 \quad 11.06<\mathbf{0 . 0 0 1}$

$\begin{array}{lll}\text { Lux } \times \text { Month } & 23.09 \quad \mathbf{0 . 0 1 7}\end{array}$

h) B. bufo

$\begin{array}{llll}\text { Heterogeneity } & -0.53 & 2.09 & 0.148\end{array}$

$\begin{array}{lrrr}\text { Height } & 0.48 & 15.64 & <\mathbf{0 . 0 0 1}\end{array}$

$\begin{array}{llll}\text { Temperature } & -0.19 & 5.04 & \mathbf{0 . 0 2 5}\end{array}$

i) H. italicus

Month

Humidity

Lux

Temperature

Hum $\times$ Month

Temp $\times$ Month

$\begin{array}{rrr} & 140.2 & <\mathbf{0 . 0 0 1} \\ -2.65 & 4.3 & \mathbf{0 . 0 3 9} \\ -20.79 & 7.6 & \mathbf{0 . 0 0 6} \\ 0.25 & 1.4 & 0.238 \\ & 30.6 & \mathbf{0 . 0 0 1} \\ 31.2 & \mathbf{0 . 0 0 1}\end{array}$
species identified by

GLM (only for species studied in this work). 